\title{
Adubação foliar de boro em dois híbridos de canola
}

\author{
Anderson Bergamasco HRYCZYNA ${ }^{1}$, Tiago Roque Benetoli da SILVA ${ }^{1 *}$, \\ Lucas AMBROSANO ${ }^{1}$, Gesmila Karoline ZAMPRONIO ${ }^{1}$ \\ 1Programa de pós-graduação em Agronomia, Universidade Estadual de Maringá, Maringá, PR, Brasil. \\ *E-mail: trbsilva@uem.br \\ (ORCID: 0000-0001-7010-1868; 0000-0002-2015-2103; 0000-0001-6657-9156; 0000-0003-4116-8961)
}

Recebido em 10/06/2021; Aceito em 21/12/2021; Publicado em 23/12/2021.

\begin{abstract}
RESUMO: A canola (Brassica napus L. var oleifera) é uma oleaginosa, pertencente à família Brassicaceae, resultado do cruzamento interespecífico entre repolho silvestre (Brassica oleracea L.) e mostarda (Brassica rapa L., syn. campestris). O boro é considerado um micronutriente, que atua na translocação de açúcares, formação de proteínas, crescimento do tubo polínico, germinação dos grãos de pólen, desenvolvimento das sementes e das paredes celulares. O objetivo desta pesquisa foi estudar as interferências nos componentes produtivos de dois híbridos de canola com a aplicação de adubação com boro por via foliar. Para tanto, instalou-se um experimento em condições de campo num delineamento experimental de blocos ao acaso em arranjo fatorial 2 × 3. Utilizou-se os híbridos Hyola 433 e Hyola 575 CL e três doses de boro foliar $(0 ; 100 ; 200) \mathrm{g} \mathrm{ha}^{-1} \mathrm{de} \mathrm{B}$. As seguintes características foram avaliadas: número de plantas, número de síliquas por planta, massa de parte aérea, massa de 100 grãos e produtividade. Com a aplicação de boro houve aumento da massa de grãos independente do híbrido. Para produtividade houve aumento somente para o híbrido Hyola 433, sendo a maior produtividade alcançada na dose de $200 \mathrm{~g} \mathrm{ha}^{-1}$. O híbrido Hyola $575 \mathrm{CL}$ não teve sua produtividade alterada com a aplicação de boro.

Palavras-chave: ácido bórico; Brassica napus L. var. oleiffera; colza; massa de 100 grãos; oleaginosa.
\end{abstract}

\section{Leaf boron fertilization in two rapessed}

\begin{abstract}
Rapessed (Brassica napus L. var oleifera) is an oilseed, belongs to Brassicaceae family, resultated between inter specific crossing of wild cabbage (Brassica oleracea L.) and mustard (Brassica rapa L., syn. campestris). Boron is considered a micronutrient, acting in sugars translocation, protein formation, pollen tube growth, pollen grain germination, seeds and cell wall development. The aimed was to study the interferences in productive components of two rapessed hybrids with application of boron fertilization by leaf application. For this, a field experiment was installed by using experimental design of randomized blocks in a 2 × 3 factorial scheme. Hyola 433 and Hyola 575CL hybrids and three doses of leaf boron $(0 ; 100$ and 200$) \mathrm{g} \mathrm{ha}^{-1}$ of B were used. The following characteristics were evaluated: plants number, number of pods per plant, mass of one hundred grains and yield. With boron application there was an increase in grain mass independent of the hybrid. In relation grain yield there was increase only for Hyola 433 hybrid, with the highest yield reached at $200 \mathrm{~g} \mathrm{ha}^{-1}$. The Hyola 575CL hybrid did not have its productivity altered with the application of boron.
\end{abstract}

Keywords: boric acid; Brassica napus L. var. oleifera; mustard; mass of a hundred grass; oilseeds.

\section{INTRODUÇÃO}

A colza (Brassica napus. L.) é uma planta da família Brassicaceae e seus grãos possuem de 24 a $27 \%$ de proteína e $38 \%$ de óleo. Sendo assim, é uma planta com alto potencial para a alimentação humana e animal e produção do biodiesel (TOMM, 2007).

A canola é produto do melhoramento genético da colza que surgiu devido ao cruzamento interespecífico entre a mostarda (Brassica rapa L.) e o repolho selvagem (Brassica oleracea L.). O termo canola é uma abreviação de "Canadian Oil Low Acid”, que significa óleo de colza com baixo teor de ácido erúcico. O óleo de canola é considerado saudável para alimentação humana, devido a ter em sua composição ômega 3, que atua na redução de triglicerídeos e no controle da arteriosclerose; possui baixo teor gordura saturada, que auxilia no controle do colesterol; também é rico em vitamina E (FOOD INGREDIENTS BRASIL, 2012; MENDONÇA et al., 2016).

Segundo Silva et al. (2017), o balanço energético da cultura da canola voltado para o biodiesel é positivo, sendo despendida $7.146 .537 \mathrm{kcal}$ para a geração de $9.930 .000 \mathrm{kcal}$ (40\% de óleo e 60\% torta), gerando assim um balanço energético de 1,39, considerando uma produtividade média de $1.500 \mathrm{~kg} \mathrm{ha}^{-1}$.

Além disso, a cultura possui inúmeras vantagens e potencialidades econômicas aos produtores, podendo ser integrada em sistemas de rotação, promover a descompactação do solo e favorecer a fixação biológica de nitrogênio. Contudo, devido às inúmeras condições climáticas e edáficas presentes no Brasil, diversas regiões à cultura canola ainda carecem de informações técnicas (ESTEVEZ et al., 2014).

Nos vegetais, o boro é considerado um micronutriente, pois a concentração desse nutriente é muito baixo nas plantas, apresentando-se na ordem de miligramas de boro por quilograma de matéria seca; no entanto, ele é essencial para o completo crescimento e reprodução dos vegetais. Sua disponibilidade é essencial para germinação dos grãos de pólen e crescimento do tubo polínico, apresenta também função na translocação de açúcares por meio do complexo 
açúcar/borato, que, por sua vez, tem relação na formação de proteínas; além disso, o boro também está presente na formação de paredes celulares e no desenvolvimento de sementes (LOPES, 1998; RAIJ, 2011).

Alguns nutrientes possuem características de pouca mobilidade no interior da planta, entre eles estão o boro, ferro e o cálcio; quando ocorre deficiência de alguns desses nutrientes, a planta tem a tendência de apresentar sintomas em folhas novas e regiões de crescimentos em geral. Como característica, o boro tende a apresentar necrose escura em folhas novas, perda da dominância apical e, por consequência, super brotação lateral, no entanto, com o passar do tempo os ápices terminais ao longo dessas ramificações tendem a apresentar necrose também, os caules também são afetados, ficando rígidos e quebradiços. Os frutos, tubérculos e raízes carnosas podem apresentar desse deformações e até necroses (TAIZ; ZEIGER, 2016).

Segundo Tomm (2003), os micronutrientes mais exigidos pela cultura da canola são o boro, molibdênio e o zinco. Estes estão ligados aos processos de floração e enchimentos de grãos. O quadro sintomatológico da deficiência de boro descrito por Haag et al. (1983) consiste em iniciar pelas folhas intermediárias, as quais apresentam aspecto ondulado e coloração amarelada na borda; com a evolução da deficiência, as folhas intermediárias se enrolam e ocorre a parada completa do desenvolvimento das folhas jovens, que se apresentam rendilhadas, enroladas e cobertas por cera.

O presente trabalho teve como objetivo avaliar as respostas dos componentes produtivos de dois híbridos de canola com a utilização da adubação boratada por via foliar na condição de campo.

\section{MATERIAL E MÉTODOS}

O experimento foi desenvolvido no campus regional da Universidade Estadual de Maringá (UEM), no município de Umuarama, Estado do Paraná, nas coordenadas geográficas

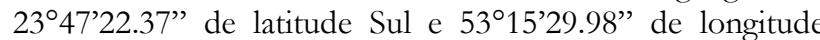
Oeste, na altitude de $401 \mathrm{~m}$. O solo da área é classificado como Latossolo Vermelho distrófico (EMBRAPA, 2018) de textura média.

Antes da instalação do experimento foi realizada análise química do solo da área, na profundidade de 0,0-0,20 m, representada na Tabela 1. A região apresenta clima Cfa ou subtropical, segundo a classificação de Köppen (NITSCHE, et al., 2019). Durante o período experimental ocorreu baixa precipitação como pode ser observado pela Tabela 2 .

Tabela 1. Atributos químicos do solo do local antes da implantação do experimento, na camada de $0-20 \mathrm{~cm}$.

Table 1. Chemical attributes of the soil of the site before the implementation of the experiment, in the $0-20 \mathrm{~cm}$ layer.

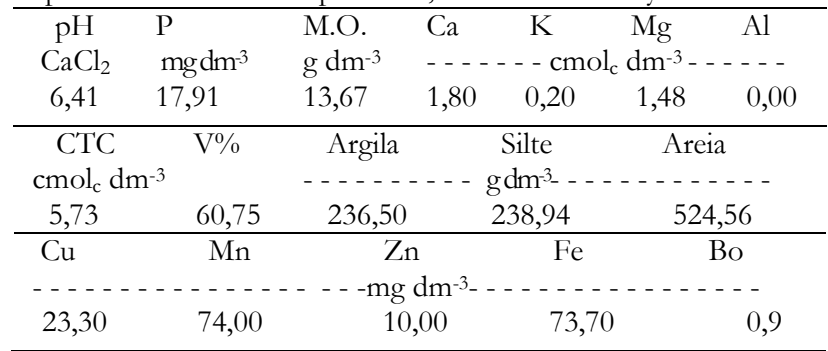

P e $\mathrm{K}$ extraídos com resina; Matéria Orgânica extraída pelo método de Walkley-Black; $\mathrm{Ca}, \mathrm{Mg}$ e Al extraídos com $\mathrm{KCl} 1 \mathrm{cmol} \mathrm{L}^{-1}$.
Tabela 2. Parâmetros meteorológicos coletados pela estação da Universidade Estadual de Maringá, no Campus Regional de Umuarama, média dos meses de abril a agosto de 2019.

Table 2. Meteorological parameters collected by the Maringá State University station, at the Umuarama Regional Campus, average from April to August 2019.

\begin{tabular}{lcccccccc}
\hline Mês & $\begin{array}{c}\text { Tmax } \\
\left({ }^{\circ} \mathrm{C}\right)\end{array}$ & $\begin{array}{c}\text { Tmed } \\
\left({ }^{\circ} \mathrm{C}\right)\end{array}$ & $\begin{array}{c}\text { Tmin } \\
\left({ }^{\circ} \mathrm{C}\right)\end{array}$ & $\begin{array}{c}\text { UR } \\
\text { MED } \\
(\%)\end{array}$ & $\begin{array}{c}\text { TPO } \\
\left({ }^{\circ} \mathrm{C}\right)\end{array}$ & $\begin{array}{c}\text { TPO } \\
\text { med } \\
\left({ }^{\circ} \mathrm{C}\right)\end{array}$ & $\begin{array}{c}\text { TPO } \\
\text { min } \\
\left({ }^{\circ} \mathrm{C}\right)\end{array}$ & $\begin{array}{c}\text { Preci- } \\
\text { pitação } \\
(\mathrm{mm})\end{array}$ \\
\hline Abril & 31,0 & 23,7 & 18,0 & 77,3 & 24,3 & 18,9 & 16,3 & 18,6 \\
Maio & 26,7 & 21,2 & 17,1 & 80,8 & 19,8 & 16,5 & 13,2 & 128,0 \\
Junho & 28,1 & 21,1 & 15,3 & 71,1 & 15,9 & 12,4 & 8,8 & 39,6 \\
Julho & 25,5 & 18,1 & 11,9 & 66,1 & 10,3 & 5,9 & 1,4 & 29,8 \\
Agosto & 28,8 & 20,9 & 13,6 & 54,4 & 10,1 & 5,1 & $-0,6$ & 3,6 \\
Media & & & & & & & & \\
/Total & 28,0 & 21,0 & 15,2 & 69,9 & 16,0 & 11,8 & 7,8 & 219,6 \\
\hline
\end{tabular}

Fonte: CAU/CCA, 2020. Temperatura máxima (Tmax); temperatura média (Tmed); temperatura mínima (Tmin); umidade relativa médio (UR MED); temperatura no ponto de orvalho máxima (TPO max); temperatura no ponto de orvalho media (TPO med); temperatura no ponto de orvalho mínima (TPO min); precipitação.

As sementes foram obtidas por meio da Embrapa Trigo do Rio Grande do Sul. A implantação da cultura ocorreu na data de 01/04/2019, a adubação de base foi realizada de acordo com análise de solo e recomendação de Pauletti; Motta (2017). A adubação de base foi realizada utilizando-se $20 \mathrm{~kg} \mathrm{ha}^{-1}$ de nitrogênio (ureia como fonte) e $40 \mathrm{~kg} \mathrm{ha}^{-1} \mathrm{de}$ $\mathrm{K}_{2} \mathrm{O}$ ( $\mathrm{KCl}$ como fonte).

Foram utilizados dois híbridos no experimento, o Hyola 433 e Hyola 575CL. O ciclo da Hyola 433 desde à emergência até a maturação ocorre entre 120 a 150 dias, assim é classificada como planta de ciclo precoce, possui ainda altura média de $120 \mathrm{~cm}$, requer solos corrigidos e corretamente adubados para expressar seu potencial produtivo. O ciclo da Hyola 575CL desde a emergência até à maturação ocorre entre 123 a 158 dias, classificada também como ciclo precoce, além disso, possui a tecnologia Clearfield $\AA$, que confere a resistência aos herbicidas do grupo das imidazolinonas (HRAC grupo B) e ainda possui resistência ao fungo Leptosphaeria maculans, causador da doença canela preta na canola (EMBRAPA, 2016).

O experimento foi arranjado em esquema fatorial $2 \times 3$, dispostos em blocos ao acaso, com quatros repetições. Os tratamentos, com doses de boro foliar $0 \mathrm{~g} \mathrm{ha}^{-1} \mathrm{de} \mathrm{B}, 100 \mathrm{~g}$ ha1 de $\mathrm{B}$ e $200 \mathrm{~g} \mathrm{ha}^{-1}$ de B. A aplicação das doses de boro ocorreu no início da emissão do botão floral. A fonte de boro utilizada foi ácido bórico (17\% de B) e a aplicação foi realizada com um pulverizador costal com cilindro de $\mathrm{CO}_{2}$.

Cada unidade experimental foi constituída de quatro linhas de 1,5 metros de comprimento, espaçadas em 0,20 m entre elas, considerando como área útil as duas linhas centrais, desprezando-se $0,25 \mathrm{~m}$ de ambas as extremidades. A colheita foi realizada de forma manual na data de 12/08/2019.

No decorrer do experimento, para o controle de plantas daninhas, foi realizada capina manual até o fechamento das entrelinhas da lavoura e para o controle de insetos-pragas foram aplicados inseticidas registrados para a cultura, no Ministério da Agricultura, Pecuária e Abastecimento e não houve a ocorrência de doenças.

As variáveis avaliadas foram: população final de plantas, matéria seca da parte aérea, número de síliquas por planta e massa de 100 grãos e produtividade. 
Para a determinação da população final de plantas e matéria seca da parte área foram coletadas as plantas na área útil de cada parcela; em seguida, separadas a parte aérea e o sistema radicular, contados e também o valor convertido para hectare. Posteriormente, as plantas foram acondicionadas em sacos de papel e secas em estufa de ventilação forçada a $60 \pm$ $5{ }^{\circ} \mathrm{C}$; após 48 horas, realizou-se a pesagem e os dados foram convertidos para $\mathrm{kg} \mathrm{ha}^{-1}$.

Para determinação do número de síliquas foram coletadas dez plantas na ocasião da colheita; na sequência, as síliquas foram contadas e calculou-se a média de síliquas por planta para cada parcela.

Para produtividade em $\mathrm{kg} \mathrm{ha}^{-1}$ foram colhidas as plantas da área útil de cada parcela experimental, com debulha das síliquas e pesagem. Foram separados os grãos para a determinação da massa de 100 grãos, através da pesagem de duas subamostras para cada repetição empregada. Ambas as avaliações foram padronizadas a 13\% de umidade (BRASIL, 2009).

Foi realizada a análise de variância ao nível de 5\% de probabilidade de erro. As médias das doses foram comparadas por regressão linear e as médias dos híbridos foram comparadas pelo teste de Tukey, ambos ao nível de $5 \%$ de probabilidade de erro. As análises estatísticas foram realizadas com o auxílio do programa Sisvar (FERREIRA, 2011).

\section{RESULTADOS}

Houve interação significativa para os parâmetros população final de plantas e da massa seca da parte área, logo, houve a necessidade de proceder o desdobramento. Para a população final de plantas, observou-se somente diferença entre os híbridos na dose de $200 \mathrm{~g} \mathrm{ha}^{-1}$ de boro (Tabela 3), onde o híbrido Hyola 433 teve maior população final. Para doses, somente o híbrido Hyola 433 se ajustou significativamente na equação linear crescente $\mathrm{Y}=1146,3 \mathrm{x}$ + 419375. A massa seca da parte área demostra que não houve efeito das doses aplicadas de boro (Tabela 3) e entre os híbridos também não houve diferença significativa.

Tabela 3. Desdobramento da interação significativa entre doses de boro e híbridos de canola (Hyola 433 e Hyola 575CL), na população final de plantas (número) e massa seca da parte aérea $\left(\mathrm{t} \mathrm{ha}^{-1}\right)$.

Table 3. Unfolding of the significant interaction between boron doses and canola hybrids (Hyola 433 and Hyola 575CL) in the final plant population (number) and shoot dry mass $\left(\mathrm{t} \mathrm{ha}^{-1}\right)$.

\begin{tabular}{lccccc} 
& & \multicolumn{2}{c}{$\begin{array}{c}\text { População final de plantas } \\
\text { (número) }\end{array}$} & \multicolumn{2}{c}{$\begin{array}{c}\text { Massa seca da parte } \\
\text { aérea }(\mathrm{t} \mathrm{ha}-1)\end{array}$} \\
Híbridos & & Hyola & Hyola & Hyola & Hyola \\
& & 433 & $575 \mathrm{CL}$ & 433 & $575 \mathrm{CL}$ \\
\hline \multirow{2}{*}{$\begin{array}{c}\text { Doses } \\
\left(\mathrm{g} \mathrm{ha}^{-1}\right)\end{array}$} & 100 & $533.250 \mathrm{a}$ & $532.250 \mathrm{a}$ & $4,3 \mathrm{a}$ & $5,2 \mathrm{a}$ \\
& $200.250 \mathrm{a}$ & $533.250 \mathrm{a}$ & $5,0 \mathrm{a}$ & $3,8 \mathrm{a}$ \\
& & $662.500 \mathrm{a}$ & $418.750 \mathrm{~b}$ & $4,7 \mathrm{a}$ & $4,4 \mathrm{a}$ \\
& $*$ & n.s. & n.s. & n.s. \\
\hline \multicolumn{3}{c}{ C.V. $=16,9 \%$} & \multicolumn{2}{c}{ C.V. $=18,3 \%$} \\
\hline
\end{tabular}

Médias seguidas de mesma letra, na linha, não diferem entre si pelo teste de Tukey a $5 \%$ de probabilidade. C.V. $=$ Coeficiente de variação

$*_{\mathrm{y}}=1146,3 \mathrm{x}+419375 \mathrm{R}^{2}=0,95^{*}$

n.s. = equação não significativa a $5 \%$ de probabilidade.

A massa de 100 grãos não apresentou interação significativa (Tabela 4), no entanto, para as doses de boro, houve aumento da densidade de grãos em função do incremento com boro e não houve diferença entre os híbridos.
Tabela 4. Efeito de doses de boro e híbridos de canola (Hyola 433 e Hyola 575CL) e na massa de 100 grãos (gramas).

Table 4. Effect of boron doses and canola hybrids (Hyola 433 and Hyola 575CL) and on the mass of 100 grains (grams).

\begin{tabular}{lc}
\hline Doses de boro $\left(\mathrm{g} \mathrm{ha}^{-1}\right)$ & Massa de 100 grãos (gramas) \\
\hline 0 & $0,21 *$ \\
100 & 0,23 \\
200 & 0,25 \\
\hline Híbridos \\
\hline Hyola 433 \\
Hyola 575CL & $0,22 \mathrm{a}$ \\
\hline
\end{tabular}

\section{C.V. $=15,2 \%$}

$* \mathrm{y}=0,0002 \mathrm{x}+0,21 \quad \mathrm{R}^{2}=1$. Equação significativa a $5 \%$ de probabilidade Médias seguidas de mesma letra no parâmetro híbridos, não diferem entre si pelo teste de Tukey a $5 \%$ de probabilidade.

Para o número de síliquas houve diferença somente entre os híbridos (Tabela 5). Na ausência de aplicação de boro, o híbrido 433 teve menor quantidade de síliquas por planta; já com a aplicação de $100 \mathrm{~g} \mathrm{ha}^{-1}$ de boro, o híbrido Hyola 443 superou estatisticamente o híbrido Hyola 575 CL; na dose $200 \mathrm{~g} \mathrm{ha}^{-1}$, não houve diferença significativa entre os híbridos.

O desdobramento da interação significativa da produtividade (Tabela 5) demonstra que sem a aplicação de boro o híbrido Hyola 433 teve produtividade menor que o híbrido Hyola 575 CL; já com a aplicação de boro, o híbrido Hyola 433 aumentou sua produção superando o híbrido Hyola 575 CL. A produtividade do híbrido Hyola 433 ajustou significativamente a equação linear $\mathrm{y}=1,6875 \mathrm{x}+75,917$, indicando que este híbrido tem maior necessidade de boro para atingir seu ápice produtivo.

Tabela 5. Desdobramento da interação significativa entre doses de boro e híbridos de canola (Hyola 433 e Hyola 575CL) no número de síliquas por planta e na produtividade de grãos $\left(\mathrm{kg} \mathrm{ha}^{-1}\right)$.

Table 5. Unfolding of the significant interaction between boron doses and canola hybrids (Hyola 433 and Hyola 575CL) in the number of pods per plant and grain yield $\left(\mathrm{kg} \mathrm{ha}^{-1}\right)$.

\begin{tabular}{lccccc}
\hline \multirow{3}{*}{ Híbridos } & \multicolumn{2}{c}{$\begin{array}{c}\text { Número de síliquas por } \\
\text { planta (número) }\end{array}$} & \multicolumn{2}{c}{$\begin{array}{c}\text { Produtividade } \\
\text { (kg ha-1) }\end{array}$} \\
& & Hyola433 & Hyola & Hyola & Hyola \\
& 0 & $24,5 \mathrm{~b}$ & $45,0 \mathrm{a}$ & $76,5 \mathrm{~b}$ & $210,7 \mathrm{a}$ \\
Doses & 100 & $71,6 \mathrm{a}$ & $39,3 \mathrm{~b}$ & $243,5 \mathrm{a}$ & $204,7 \mathrm{~b}$ \\
$\left(\mathrm{~g} \mathrm{ha}^{-1}\right)$ & 200 & $59,5 \mathrm{a}$ & $48,3 \mathrm{a}$ & $414,0 \mathrm{a}$ & $171,9 \mathrm{~b}$ \\
& n.s. & n.s. & $*$ & n.s. \\
\hline & \multicolumn{3}{c}{ C.V. $=24,9 \%$} & \multicolumn{3}{c}{ C.V. $=41,4 \%$} \\
\hline
\end{tabular}

Médias seguidas de mesma letra, na linha, não diferem entre si pelo teste de Tukey a $5 \%$ de probabilidade. C.V. $=$ Coeficiente de variação $*_{\mathrm{y}}=1146,3 \mathrm{x}+419375 \mathrm{R}^{2}=0,95 *$

n.s. $=$ equação não significativa a $5 \%$ de probabilidade.

\section{DISCUSSÃO}

Segundo Mendonça et al. (2016), a cultura da canola necessita de $310 \mathrm{~mm}$ de precipitação para seu completo desenvolvimento e nesse experimento ocorreu 219,6 mm (Tabela 2), ocasionando déficit hídrico. A aplicação de boro auxiliou na sobrevivência do híbrido 433 no período de estresse hídrico. Fujiyama (2019) identificou que a adubação bórica promoveu maior eficiência fotossintética, trocas gasosas mais eficientes e maior eficiência no uso da água na cultura da soja, o nível de $0,38 \mathrm{mg} \mathrm{dm}^{-3}$ de B extraível com água quente proporcionou maior eficiência do uso da água. Castro et al. (2006) trabalhando com estresse hídrico na produção de girassol, concluíram que, independentemente do estresse hídrico, a aplicação do boro aumentou o 
rendimento. Silva et al. (2015) relatam que a nutrição por boro aumenta a tolerância ao déficit hídrico em clones de eucalipto.

Dentro da dose de $200 \mathrm{~g} \mathrm{ha}^{-1}$, observa-se que o híbrido Hyola 433 é mais responsivo à aplicação de boro quando comparado ao híbrido Hyola 575CL. Para a cultura da canola, as relações entre estresse hídrico e adubação bórica ainda não são bem explicadas pela literatura agronômica, mas pelo resultado obtido, sugere-se que o híbrido Hyola 433 respondeu à aplicação de boro, mesmo em condições de estresse hídrico.

Na literatura agronômica é relatado que aplicação do boro não altera a massa de parte área ou até em alguns casos pode até diminuir. Euba et al (2014) estudando a aplicação do B na cultura do girassol, relatam que não houve diferença significativa na massa seca de folhas e caule. Pegoraro et al (2008) estudando a aplicação de B na cultura da soja em diferentes tipos de solo, relatam que houve diminuição da massa seca da parte aérea com a aplicação de B. A aplicação de boro na canola não alterou a massa seca de parte área que o que corrobora com os resultados obtidos em outras espécies vegetais.

O incremento da massa de 100 grãos com a aplicação de boro pode estar relacionado a maior eficiência na polinização da cultura da canola. Novais et al., (2007) demostram que o boro possui funções ligadas às regiões de crescimento, tendo sua importância em processos de florescimento, crescimento do tubo polínico e frutificação. Zhang et al. (2017) relatam que genes responsáveis pelo transporte de $\mathrm{B}$ em plantas de colza, são predominantemente expressos nas raízes, gemas florais, flores, anteras e pistilos. Cuchiara et al. (2015) trabalhando com a viabilidade polínica in vitro em mamona, identificaram que a presença de $4 \mathrm{mg} \mathrm{L}^{-1}$ de $\mathrm{B}$ associado com sacarose em meios de cultura, favorece a germinação dos grãos de pólen. Mussury;

Hernández; López (2005) analisando a relação entre o boro e as proteínas estruturais da parede celular do pólen in vitro de milho, tabaco, pinus, Lilum longiflorum e Impatiens sp., em todas as espécies analisadas, notaram a presença de B no meio da germinação aumentou o comprimento do tubo polínico depois da germinação e concluíram que este aumento pode estar ligado ao acúmulo de glicoproteínas ricas em hidroxiprolina, ligadas às paredes celulares do tubo polínico. Fernandes (2000) estudando os processos de polinização da canola, relatam que apesar da canola ser uma planta autógama, apresenta também recursos para alogamia, como abundância de pólen, néctar e odor. Relatam também que com a ocorrência da polinização há aumento do peso de sementes, indicando, assim, que há maior quantidade de reserva nutricional na semente que favorece a germinação.

No entanto, outras espécies oleaginosas não apresentam incremento na massa de 100 grãos com a aplicação de boro. Lima et al. (2013) trabalhando em girassol, relatam que a massa de 1.000 aquênios não foi influenciada pela aplicação bórica. Calonego et al. (2010) demostram que para a cultura da soja a aplicação foliar de boro não altera a massa de 100 grãos de soja. Mantovani et al. (2013) analisando a adubação foliar em amendoim constataram que não houve alteração na massa 100 grãos.

Por tanto, diferentemente de outras oleaginosas, a massa de 100 grãos da canola apresenta resposta positiva à adubação bórica; isso pode ocorrer devido ao boro ser essencial para diversos processos ligados ao florescimento e à polinização das plantas, visto que a canola apresenta dependência de polinização para atingir o seu máximo potencial; no entanto, para elucidação da correlação entre os processos envolvidos no aumento da massa de 100 grãos e com a aplicação foliar de boro necessitará de outros estudos no futuro.

A aplicação do boro resultou na diferença entre os híbridos no número de silíquas por planta somente na dose de $100 \mathrm{~g} /$ ha onde o Hyola 433 foi superior. Já entre as doses não houve diferença, na literatura agronômica não há relatos sobre da influência do boro no número de siliquas, no entanto, Jankowski et al. (2016) relatam que aplicação de boro foliar em variedades de inverno de canola pode aumentar em $4 \%$ o número de sementes por síliquas.

Com a aplicação do boro a produtividade do híbrido Hyola 433 ajustou a regressão linear e superou a Hyola 575CL. O aumento da produtividade em um único híbrido pode estar relacionado a melhoria da eficiência da polinização nesse híbrido. Pois, a literatura aponta que há variação dos benefícios da polinização para produtividade entre diferentes cultivares de canola. Nesse sentido, Blochtein et al. (2014) apresentam diferenças na porcentagem do aumento de produtividade em híbridos de canola quando expostos à livre visitação de abelhas, os híbridos Hyola 420 e Hyola 61 teve o incremento de $17 \%$ e $30 \%$ de produtividade respectivamente, quando comparada sem a visitação de abelhas.

Os fatores envolvidos no aumento do desempenho do híbrido Hyola 433 com a aplicação do boro não são bem elucidados, no entanto, o B é um micronutriente que está envolvido no processo de polinização, principalmente do desenvolvimento do tubo polínico; já a cultura da canola em geral possui aumento de produtividade pela polinização. Assim, é possível que para esse híbrido possa ocorrer sinergia entre a aplicação de B e a polinização pela livre visitação das abelhas.

\section{CONCLUSÕES}

A aplicação de boro proporcionou acréscimo da massa de 100 grãos dos dois híbridos. Somente o híbrido Hyola 433 obteve acréscimo de produtividade com a aplicação do boro sendo a dose de $200 \mathrm{~g} \mathrm{ha}^{-1}$ a maior produtividade. Portanto, o híbrido Hyola 433 respondeu positivamente à aplicação de doses de boro via foliar, enquanto o híbrido Hyola 575CL não teve seus componentes produtivos influenciados pelas doses de boro.

\section{AGRADECIMENTOS}

Á equipe do Núcleo de Estudos em Oleaginosas NEOL. Empresa Brasileira de Pesquisa Agropecuária EMBRAPA, pelo fornecimento das sementes de canola.

\section{REFERÊNCIAS}

BLOCHTEIN, B.; SILVA, P. N.; HALINSKI, R.; LOPES, L. A.; WITTER, S. Comparative study of the floral biology and of the response of productivity to insect visitation in two rapeseed cultivars (Brassica napus L.) in Rio Grande do Sul. Brazilian Journal of Biology, v. 74, n. 4, p. 787-794, $2014 . \quad$ DOI: https://doi.org/10.1590/1519-6984.02213.

BRASIL. Regras para análises de sementes. 1 ed. Brasília: Ministério da Agricultura, Pecuária e Abastecimento. Secretaria de Defesa Agropecuária, 2009. 398p.

CALONEGO, J. C.; OCANI, K.; OCANI, M.; SANTOS, C. H. Adubação boratada foliar na cultura da soja. Colloquium Agrariae, v. 6, n. 2, p. 20-26, 2010. DOI: DOI:10.5747/ca.2010.v06.n2.a054. 
CASTRO, C.; MOREIRA, A.; OLIVEIRA, R. F.; DECHEN, A. R. Boro e estresse hídrico na produção do girassol. Ciência e Agrotecnologia, v. 30, n. 2, p. 214 220, 2006. DOI: https://doi.org/10.1590/S141370542006000200004

CAU/CCA_Campus Regional de Umuarama / Departamento de Ciências Agronômicas - UEM. Série de Dados Climatológicos. Disponível em: $<$ http://www.dca.uem.br/1clima.htm> Acesso em: 06 abril 2020.

CUCHIARA, C. C.; JUSTO, P. S.; SCHMITZ, J. D.; BOBROWSKI, V. L. Pollen germination and viability of castor bean (Ricinus communis L.): culture medium composition and environmental conditions. Científica, v. 43 , n. 1, p. 1-7, 2015. DOI: http:/ /dx.doi.org/10.15361/1984-5529.2015v43n1p1-7.

EMBRAPA_Empresa Brasileira De Pesquisa Agropecuária. Canola híbridos convencionais e com resistência a Cleareld®. 2016. Disponível em: < https://ainfo.cnptia.embrapa.br/digital/bitstream/item /142262/1/ID43652-2016FD394.pdf > . Acesso em: 02 fev. 2021.

EMBRAPA_Empresa Brasileira De Pesquisa Agropecuária. Sistema Brasileiro de Classificação dos Solos. Rio de Janeiro: EMBRAPA/CNPSO, 2018. 532p.

ESTEVEZ, R. L.; DUARTE, J. B.; CHAMBO, A. P. S.; CRUZ, M. I. F. A cultura da canola (Brassica napus var. oleifera). Scientia Agraria Paranaensis, v. 13, n. 1, p. 1 9, 2014. DOI: https://doi.org/10.18188/sap.v13i1.8177.

EUBA NETO, M.; FRAGA, V. S.; DIAS, B. O.; SOUTO, J. S. Efeito de doses de boro no crescimento vegetativo de girassol em diferentes classes de solos. Revista ceres, v. 61, n. 3, p. 399-405, 2014. DOI: https://doi.org/10.1590/S0034-737X2014000300015.

FERREIRA, D. F. Sisvar: a computer statistical analysis system. Ciência e Agrotecnologia, v. 35, n. 6, p. 10391042, 2011. DOI: https://doi.org/10.1590/S141370542011000600001.

FOOD INGREDIENTS BRASIL. Canola uma variação genética mundialmente apreciada. Revista-Fi, n. 21, 2012. DOI: 2016060774259001464978807.pdf

FUJIYAMA, B. S.; SILVA, A. R. B.; JÚNIOR, M. L. S.; CARDOSO, N. R. P.; FONSECA, A. B.; VIANA, R. G.; SAMPAIO, L. S. Boron fertilization enhances photosynthesis and water use efficiency in soybean at vegetative growth stage. Journal of Plant Nutrition, v. 42, n. 19, p. 2498-2506, 2019. DOI: https://doi.org/10.1080/01904167.2019.1659326.

HAAG, H. P.; CASARINI, S. M. A. G.; DECHEN, A. R. Nutrição mineral da colza (Brassica napus L.). Anais Da Escola Superior De Agricultura Luiz De Queiroz, v. 40, n. $1, \quad$ p. $87-94$, 1983. DOI: https://doi.org/10.1590/S0071-12761983000100003

HERNANDEZ, E. D. R. G.; LOPES, G. I. C. Structural cell wall proteins from five pollen species and their relationship with boron. Brazilian Journal of Plant Physiology, v. 17, n. 4, p. 375-381, 2005. DOI: https://doi.org/10.1590/S1677-04202005000400005.

JANKOWSKI, K. J.; SOKÓLSKI, M.; DUBIS, B.; KRZEBIETKE, S.; ŻARCZYŃSKI, P., HULANICKI, P.; HULANICKI, P.S. Rendimento e qualidade das sementes de estupro de oleosa de inverno (Brassica napus L.) em resposta à aplicação foliar de boro. Ciências
Agrícolas e Alimentícias, v. 25, n. 3 p. 164-176, 2016. DOI: https://doi.org/10.23986/afsci.57413

LIMA, A. D.; VIANA, T. V. A.; AZEVEDO, B. M.; MARINHO, A. B.; DUARTE, J. M. L. Adubação borácica na cultura do girassol. Revista Agro@mbiente, v. 7, n. 3, p. 269-276, 2013. DOI: http://dx.doi.org/10.18227/1982-8470ragro.v7i3.1237.

LOPES, A. S. Manual internacional de fertilidade do solo. 2 ed. Piracicaba: Editora Potafos, 1998. 177p.

MANTOVANI, J. P. M.; CALONEGO, J. C.; FOLONI, J. S. S. Adubação foliar de boro em diferentes estádios fenológicos da cultura do amendoim. Revista Ceres, v. 60, n. 2, p. 270-278, 2013. DOI: https://doi.org/10.1590/S0034-737X2013000200017

MENDONÇA, J. A. RIBOLDI, L. B.; SOARES, C. D. F.; CASTRO, P. R. C.; KLUGE, R. A. Canola (Brassica napus L.). Série Produtor Rural, $\mathrm{n}^{\circ}$ 61. Piracicaba: ESALQ - Divisão de Biblioteca, 2016. 32p.

MUSSURY, R. M.; FERNANDES, W. D. Studies of the floral biology and reproductive system of Brassica napus $\mathrm{L}$. (Cruciferae). Brazilian Archives of Biology and Technology, v. 43, n. 1, p. 71-77, 2000. DOI: https://doi.org/10.1590/S1516-89132000000100014

NITSCHE, P. R.; CARAMORI, P. H.; RICCE, W. S.; PINTO, L.F.D. Atlas climático do estado do Paraná. Londrina: Instituto Agronômico do Paraná, 2019. 210p.

NOVAIS, R. F.; ALVARES, V. H.; BARROS, N. F.; FONTES, R. L. F.; CANTARUTTI, R. B.; NEVES, J. C. L. Fertilidade do solo. 1 ed. Viçosa: Sociedade Brasileira de Ciência do Solo, 2007. 1017p.

PAULETTI, V.; MOTTA, A. C. V. Manual de adubação e calagem para o estado do Paraná. Curitiba: SBCS/NEPAR, 2017. 482p.

PEGORARO, L. F. L.; SANTOS, J. A.; SILVA, I. R.; FONTES, R. L. F.; FARIA, A. F.; MOREIRA, F. F. Crescimento de soja em solos em resposta a doses de boro, calagem e textura do solo. Ciência agropecuária, v. 32 , n. 4, p. 1092-1098, 2008. DOI: https://doi.org/10.1590/S1413-70542008000400009

RAIJ, B. V. Fertilidade do solo e manejo de nutrientes. Piracicaba: International Plant Nutrition lnstitute, 2011. 420p.

SILVA, L. F. L.; GONÇALVES, W. M.; MALUF, W. R.; RESENDE, L. V.; SARMIENTO, C. M.; LICURSI, V.; MORETTO, P. Energy balance of biodiesel production from canola. Ciência Rural, v. 47, n. 2, e20151084, 2017. DOI: https://doi.org/10.1590/0103-8478cr20151084

SILVA, P. H. M.; CAMPOE, O. C.; VIERRA, I. G.; PAULA, R. C. Aplicação foliar de boro em eucalipto sob estresse hídrico. Scientia Forestalis. v. 43, n. 106, p. 395-405, 2015. DOI: http://hdl.handle.net/11449/171935

TAIZ, L.; ZEIGER, E. Fisiologia vegetal. 3 ed. Porto Alegre: Editora Artmed, 2016. 719p.

TOMM, G. G. Indicativos tecnológicos para produção de canola no Rio Grande do Sul - sistema de produção. Passo Fundo: Embrapa Trigo, 2007. 68p.

TOMM, G. G. Manual para cultivo de canola - cartilha. Santa Rosa: Embrapa Trigo, 2003. 22p.

ZHANG, Q; CHEN, H.; HE, M.; ZHAO, Z.; CAI, H.; DING, G.; SHI, L.; XU F. The boron transporter BnaC4.BOR1;1c is critical for inflorescence development and fertility under boron limitation in Brassica napus. Plant, Cell \& Environment, v. 40, n. 9, p. 1819-1833, 2017. DOI: https://doi.org/10.1111/pce.12987. 